\title{
Research on the Theory of Collaborative Service of National Quality Infrastructure*
}

\author{
Jingxing Liao \\ China National Institute of Standardization \\ Beijing, China
}

\author{
Lei Feng \\ China National Institute of Standardization \\ Beijing, China
}

\author{
Shaopeng $\mathrm{Wu}$ \\ China National Institute of Standardization \\ Beijing, China
}

\begin{abstract}
The development of collaborative service of national quality infrastructure is one of the main ways and methods to promote the national quality infrastructure efficiency to release fully. Through theoretical analysis, practice and summary, and other research methods, this paper analyzes and studies the connotation and characteristics of the collaborative service of national quality infrastructure, builds a theoretical framework of collaborative services consisting of participants and carriers, and initially explores and proposes two kinds of collaborative service models, in order to provide theoretical support for the construction of the collaborative service of national quality infrastructure.
\end{abstract}

Keywords-national quality infrastructure; collaborative service; theoretical basis

\section{INTRODUCTION}

National Quality Infrastructure (NQI) that consists of standards, measurement, certification and accreditation, and inspection and testing is the infrastructure of quality development. After years of development, the construction of China's NQI has made some achievements, but the efficiency of NQI has not been fully released. An important topic our country facing is how to deepen the integration and development of various elements of NQI, improve the overall efficiency of NQI, and provide the enterprises with all-round service including measurement, standard, certification and accreditation, inspection and testing.

By analyzing the connotation and characteristics of NQI collaborative service, this paper constructs a theoretical system based on the participants and carriers of collaborative service, and provides the NQI collaborative service with top-level theoretical basis, in order to provide a major theoretical support and model basis for China's systematic construction of NQI collaborative service.

*Funding project: Major Consultant and Research Project of Chinese Academy of Engineering 572017Z-5558 "Strengthen the Development Strategy of National Quality Infrastructure".

\section{CONNOTATION AND CHARACTERISTICS OF NQI COLLABORATIVE SERVICE}

\section{A. Connotation of NQI Collaborative Service}

The definition of management collaboration is that each collaborative element interacts, cooperates and synchronizes in a certain way to produce order parameters that dominate the development of the system, controls the system to develop in an orderly and stable direction, multiplies or amplifies the whole function of the system, and achieves a synergy effect of " $2+2>4 "$ ". Based on this, we define the NQI collaborative service as a process that coordinates NQI's various elements including measurement, standard, inspection and testing, and certification and accreditation, and serves the enterprise in a coordinated way. In essence, under the promotion of related guidelines and strategic planning, it can rely on the participants and service carriers, to realize the mutual cooperation, effective communication and interaction between the various elements, better exert overall strength to serve the enterprise, realize the whole process and full content service management of the enterprise's NQI, produce the synergy effect of $1+1+1+1>4$, so as to enable the enterprise to create higher values and benefits and promote economic development.

\section{B. Characteristics of NQI Collaborative Service}

1) Integrality: NQI collaborative service is composed of multiple subjects and elements. These entities and elements are not isolated and unrelated individuals, and they are closely integrated together. This kind of integration is not to simply combine and accumulate various subjects and elements, but to organically operate as an interactive and interactional integral structure and organic combination in accordance with business model and service management ideas, achieving an effect of " $1+1+1+1>4$ " from the whole system.

2) Collaboration: In the traditional NQI service, interdepartmental process requires a lot of manual re-input or transfer works, which increases the cost and reduces the overall operation efficiency. In the NQI collaborative service, each department rationally uses the links of all elements 
through effective and in-depth collaboration, which not only can complete NQI activity more efficiently, but also realize synergistic effect of time contraction, cost reduction, efficiency improvement and sustainable development.

3) Commonality: NQI collaborative service provides the enterprises with more powerful information, technologies, services, and other support and services through the sharing and integration of vertical and horizontal information. On the one hand, the resources of enterprise and quality supervision department, such as standard, measurement, certification and accreditation, inspection and testing, will be shared. On the other hand, other social resources will be integrated to diversify resources and serve enterprises efficiently.

4) Development: Development refers to that collaborative service will be dynamically adjusted and improved with the development of society. On the one hand, with the continuous change of national policies, the development strategy of collaborative services should be constantly adjusted. On the other hand, there is a strong mobility among all subjects and elements of the collaborative services, and its service content, form and system and mechanism should be adjusted at any time based on the needs of different enterprises.

\section{ANALYSIS OF NQI COLLABORATIVE SERVICE SUBJECT}

The key to developing the collaborative service is to determine the subject of collaborative services, which can provide direction guide and decision reference for the effectiveness of collaborative development. Analyzing positioning and functions of the participants in the collaborative model can better provide theoretical support for the study of collaborative service model.

The subjects of NQI collaborative service mainly include the government, the technical departments of quality supervision system, the third-party technical institutions and enterprises. The main functions of these four types of subjects are as "Table I".
TABLE I. ANALYSIS OF THE FUNCTIONS OF NQI COLLABORATIVE SERVICE SUBJECTS

\begin{tabular}{|l|l|}
\hline \multicolumn{1}{|c|}{ Participant } & \multicolumn{1}{c|}{ Functions } \\
\cline { 1 - 2 } Government & $\begin{array}{l}\text { Policy guidance, macro-control and } \\
\text { financial support }\end{array}$ \\
\cline { 1 - 2 } $\begin{array}{l}\text { Technical departments of quality } \\
\text { supervision system }\end{array}$ & $\begin{array}{l}\text { Technical support, overall planning, } \\
\text { resource sharing }\end{array}$ \\
\cline { 1 - 2 } Third-party technical institutions & $\begin{array}{l}\text { Demand feedback, achievement } \\
\text { display, economic revenue }\end{array}$ \\
\cline { 1 - 2 } Enterprises &
\end{tabular}

\section{A. Government Positioning and Functions}

The government is the commander in chief of NQI collaborative services, which mainly exerts the role of guidance and supervision. On the one hand, the government will provide policy support for quality supervision departments and the third-party technical institutions to conduct collaborative services, specify goals and directions for collaborative services, and create a good social atmosphere. On the other hand, the government will provide personnel, materials, and financial support for quality supervision department and third-party technical institutions, enhance the R\&D capabilities of the collaborative service platform, and create a favorable environment for development.

\section{B. The Positioning and Function of the Technical Department of the Quality Supervision System}

The technical department of the quality supervision system refers to the relevant departments that provide NQI services such as measurement, standard, certification and accreditation, inspection and testing in the quality supervision system. It is the core subject of NQI collaborative services, and provides technical support for the smooth development of collaborative services. In light of the different modes of collaborative services, the technical department of the quality supervision system has two orientations. First, as a provider of NQI technical services, it provides services including measurement, standard, certification and accreditation, inspection and testing, and quality management for the production of enterprises. The specific service content is shown below. "Fig. 1"

\begin{tabular}{|c|c|c|c|c|}
\hline & & Technical department of quality system & & \\
\hline Measurement service & Standard service & $\begin{array}{l}\text { Certification and } \\
\text { accreditation service }\end{array}$ & $\begin{array}{l}\text { Inspection and testing } \\
\text { service }\end{array}$ & $\begin{array}{l}\text { Quality management } \\
\text { service }\end{array}$ \\
\hline $\begin{array}{l}\text { - Measurement system } \\
\text { - Overall measurement } \\
\text { test scheme } \\
\text { - Verification and } \\
\text { calibration } \\
\text { - Valuation transfer and } \\
\text { traceability } \\
\text {-... }\end{array}$ & $\begin{array}{l}\text { - Standard system } \\
\text { - Revision of standard } \\
\text { - Standards literature retrieval } \\
\text { and novelty-search } \\
\text { - Training of standard } \\
\text { implementation and publicity } \\
\text { - Standard demonstration } \\
\text { application } \\
\text { - ... }\end{array}$ & $\begin{array}{l}\text { - Product certification } \\
\text { - System certification } \\
\text { - Service certification } \\
\text { - Approval of laboratory } \\
\text { qualification } \\
\text { - Approval of testing } \\
\text { organization } \\
\text { qualification } \\
\text {-... }\end{array}$ & $\begin{array}{l}\text { - Inspection and } \\
\text { testing agency } \\
\text { - Inspection and } \\
\text { testing report } \\
\text {-... }\end{array}$ & $\begin{array}{l}\text { - Quality training } \\
\text { - Brand creation } \\
\text { - Introduction of } \\
\text { advanced } \\
\text { management methods } \\
\text { - Construction of } \\
\text { industrial } \\
\text { demonstration area } \\
\text {-... }\end{array}$ \\
\hline
\end{tabular}

Fig. 1. Service content of technical department of the quality supervision system.

Second, as the coordination liaison for NQI collaborative services, the lead technical department in the quality supervision system can establish an important bridge between the government and the market, and between the technology sector and the enterprise, which mainly exerts the role of organizational coordination and overall planning. 


\section{The Positioning and Function of the Third-party Technical Institutions}

The positioning of the third-party technical institutions is similar to that of the technical department of the quality supervision system. For one thing, it can serve as a provider of NQI technical services; for another thing, it can serve as a coordinator of NQI collaborative services. The participation of third-party technical institutions has changed the existing problems, for example, the feedback for enterprise needs was not in time and the service range was narrow when the quality supervision department directly faced the enterprise in the past. It can closely link to enterprises and approach to enterprise, timely feedback enterprise demands, and greatly reduce the workload and work pressure of quality supervision department at the same time.

\section{Positioning and Function of Enterprise}

Enterprises are the beneficiaries of NQI collaborative services. The purpose of NQI collaborative services is to provide enterprises with more scientific, more efficient, and more convenient services to maximize economic efficiency. Therefore, as the main service target of NQI collaborative services, the enterprise plays an important role in conveying demand and returning effects. The degree of cooperation among the enterprise and the quality supervision department and the third-party technical institution directly affects the output effect of the collaborative service.

\section{The ANALYSIS OF NQI COLLABORATIVE SERVICE CARRIERS}

The NQI collaborative service carriers refer to the tools, facilities, and sites for communicating, collaborating, and interacting with the collaborative service subjects. The convenient, efficient, and orderly collaborative services needed by NQI's subject are mainly realized by carriers. The carriers of NQI collaborative services include entity service forms and information service means.

\section{A. Entity Service Carrier}

By building entity service station or unifying service hall/window, the entity service form collects and manages the actual needs that enterprise manages NQI, and provides the NQI-related one-stop service for enterprises. It mainly includes quality service station, quality service hall, service base and service card and other carrier mode.

Quality service station is generally set up in Science Park to provide enterprises with basic quality services, such as fulllifecycle measurement, standard, inspection and testing, certification and accreditation and so on. The quality supervision department provides technical and training support. The park will select quality service specialists, and establish a quality service delivery model from government to park service station to enterprise. The quality service hall is a place where NQI-related businesses are dealt by a centralized manner, and is equipped with business windows and service personnel. All NQI services enjoyed by the enterprises can be completed through "single contact" with the window personnel, so as to realize the effectiveness of NQI one-stop service hall.
The services base mainly studies and comments on the foreign technical trade measures, helps the enterprise to take part in attention, comment, communication, and counterclaim of the international technical trade measures, enables enterprises to grasp and cope with the latest international regulations, standards and information in time, and at the same time, forces enterprises to improve the quality of their export products and their competitiveness in the international market. The service cards are printed with various information such as service calls, office locations and business consulting groups, which makes it easy for business personnel to fully understand NQI-related services. It is convenient, simple and practical, and is a powerful supporting means for collaborative services.

\section{B. Information Service Carrier}

By using the modern information technologies including big data and "Internet +", the information service carrier collects and copes with the actual needs of enterprises based on website, WeChat Official Account and telephone. On the basis of a set of common information technology tools, application measures and standardized protocols, all technical departments of the quality supervision system and the thirdparty technical institutions can realize the effective sharing of information, so as to provide enterprises with convenient and unified network services and full-process NQI matter handing. It mainly includes technical service platform, information resources database, means of online publicity and promotion and other carrier modes.

The technical service platform publicizes technology service content on the network through informatization means. Enterprises can look through NQI-related information without leaving home, and carry on the operation of online testing applications, certification applications and standard inquiries, so as to realize the informatization of full business processes, such as measurement, standard, certification and accreditation, and inspection and testing. The information resource database integrates and shares the NQI data resources such as standard, measurement, authentication and verification to form an open database that is easy to refer to. The database will be as the data support of NQI technology service platform to strengthen the sharing of data between the government and enterprises. The means of online promotion and publicity refers to regularly push the latest developments, detection technologies, and related laws and regulations through information methods such as WeChat Public Account, QQ, and WeChat Group, and it can also provide consulting services for enterprises online.

\section{EXPLORATION AND ANALYSIS OF NQI COLlabORATIVE SERVICE MODE}

Through the theoretical analysis of NQI collaborative services, based on the positioning of participants and pattern of manifestation of carrier, the NQI collaborative services can be roughly divided into two modes: one is to provide NQI-related one-stop service models for enterprises by establishing entity service stations and dispatching station personnel; the other is to build a network information platform to collect actual business needs through websites, WeChat Official Accounts and telephones, and then to provide enterprises with NQIrelated one-stop services. 
In accordance with the working conditions in different locations, the third-party institutions of tangible NQI collaborative service can design the development planning, provide the enterprise with the content and way of service, coordinate all the jobs to work in a orderly way. Meanwhile, with the help of "Internet +" platform, it can quickly acquire the NQI service demands of the enterprise for the deployment of resources. The two modes of work reflect and complement each other, and can be integrated into a pattern that will be widely used and promoted in the country in the future.

\section{CONCLUSION}

NQI is a new concept. In addition, its elements, including measurement, standards, certification and accreditation, inspection and testing, are very basic, technical and professional. People do not know enough about it and know little about NQI collaborative services. Currently, there is no research on the top-level design theory of NQI collaborative service. Through literature research and case analysis, this paper studies the theoretical basis of NQI collaborative services, and proposes an NQI collaborative service system framework consisting of four major subjects, namely, government, quality supervision system, third-party technical institution and enterprise. Combined with the actual situation of collaborative service in various regions, this paper studies and analyzes the form of collaborative service carrier, and puts forward two major modes of collaborative service in China, so as to provide reference for the follow-up collaborative service practice activities.

The study of this paper provides a theoretical basis for the development of NQI collaborative service in all parts of China, as well as a reference for the establishment of a typical NQI service model throughout the country. How to put the theoretical research into the practice? In the subsequent research, the paper will further combine with the successful experiences of developed countries, develop and perfect the NQI collaborative service by connecting the practice activities in different places and promote its high development.

\section{REFERENCES}

[1] Pan Kailing, Bai Liehu. Management Collaboration Theory and Its Application Research [M]. Beijing: Economy \& Management Publishing House, 2005:112-160.

[2] Research Group of Strategy of Manufacturing Quality Power. The Basic Volume of Strategy of Manufacturing Quality Power[M]. Beijing:Standards Press of China, 2016:32-56.

[3] Feng Lei, et al. The One-Stop Service Practice of American Quality and Technology Foundation and Its Enlightenment to China [J]. Standard Science, 2017 (7) : 70-74.

[4] Chen Xi. The Enlightenment of Cross-Sector Cooperation Mechanism to Chinese Government [J]. Academic Exploration, 2015(4):23-28.

[5] Pang Jinrong.Study on collaborative and Linkage System of Logistics Industry and Manufacturing Industry Based on Service Model Innovation [D]. Beijing: Academic Exploration of Beijing University of Posts and Telecommunications, 2012. 